\title{
PowerEnergy2017-3194
}

\section{A THORETICAL AND EXPERIMENTAL STUDY OF HFE-7000 IN A SMALL SCALE SOLAR ORGANIC RANKINE CYCLE AS A THERMOFLUID}

\author{
Huseyin Utku Helvaci \\ Nano Corr, Energy and Modelling Research \\ Group \\ Bournemouth University \\ Bournemouth, UK
}

\author{
Zulfiqar Ahmad Khan \\ Nano Corr, Energy and Modelling Research \\ Group \\ Bournemouth University \\ Bournemouth, UK
}

\begin{abstract}
Renewable energy technologies and sources have been playing a key role in reducing reliance on fossil fuels and significantly reducing $\mathrm{CO}_{2}$ emissions and its footprint. $\mathrm{EU}$ initiative of generating $50 \%$ of the energy needs through sustainable sources by 2050 needs a direct response in terms of providing applied solutions to realize this target on time. Solar energy is one of the major and abundantly renewable energy sources which are free and clean. Solar energy can be utilized by means of solar Photovoltaic (PV) or solar collectors. Concentrating solar collectors supply thermal energy from medium to high grade where as non-concentrating collectors (flat plate) delivers low-grade thermal energy. The use of thermofluids with boiling temperatures lower than the water, allows the operation of low grade solar thermal systems on an Organic Rankine Cycle (ORC) to generate both mechanical and heat energy. At the same time, the selection of appropriate thermofluid is an important process and has a significant effect both on the system performance and the environment. Conventional thermofluids such as Chlorofluorocarbons (CFCs) and Hydrochlorofluorocarbons (HCFCs) have high ozone depletion (ODP) and high global warming (GWP) potential. It is therefore important to investigate novel and environmentally friendly thermofluids to address environmental impacts as global warming and ozone layer depletion. Hydrofluoroethers (HFEs) are non-ozone depleting substances and they have relatively low GWP. Therefore, HFEs can be used as a replacement for CFCs and HCFCs. In this study, a solar ORC is designed and commissioned to use HFE 7000 as a thermofluid. The proposed system consists of a flat-plate solar collector, a vane expander, a condenser and a pump where the collector and the expander are used as the heat source and prime mover of the cycle respectively. The performance of the system is determined through energy analysis. Then, a mathematical model of the cycle is developed to perform the simulations using HFE-7000 at various expander pressure. Experimental data indicated that the efficiency and the net
\end{abstract}

mechanical work output of the cycle was found to be $3.81 \%$ and $135.96 \mathrm{~W}$ respectively. The simulation results showed that increasing the pressure ratio of the cycle decreased the amount of the heat that is transferred to HFE 7000 in the collector due to the increased heat loss from the collector to the environment. Furthermore, net output of the system followed a linear augmentation as the pressure ratio of the system increased. In conclusion, both the experimental and theoretical research indicates that HFE 7000 offers a viable alternative to be used efficiently in small scale solar ORCs to generate mechanical and heat energy.

\section{INTRODUCTION}

Renewable energy sources such as solar energy can be classified as a low-grade temperature heat source and it is crucial to utilize low-grade heat sources in terms of meeting the World electricity demand [1]. Organic Rankine cycle (ORC) has the same configuration as the conventional Rankine cycle with the exception of working fluid that is used in the cycle [2]. Organic compounds with lower boiling temperature allow ORCs to utilize low-grade temperature heat sources efficiently [3]. Solar sourced ORC which consists of solar collectors such as evacuated tube (ETC), flat-plate (FPC) and parabolic trough collectors (PTC) combined with ORC unit can generate heat with temperature ranging from $80-150{ }^{\circ} \mathrm{C}$ to generate mechanical power [4].

An important number of experimental studies have been conducted to convert solar thermal energy into mechanical, as well as electric power by using solar sourced ORCs. Manolakos et al. conducted an experimental study to investigate the performance of a solar ORC employing HFC134a for reverse osmosis desalination [5-7]. A solar ORC considering FPC and ETC was investigated in [8]. In their study, HFC-245fa refrigerant was used as a working fluid and the collector efficiencies were found to be $55.2 \%$ and $71.6 \%$ respectively. A thermal efficiency of a solar ORC, including heat regeneration with the working fluid of HFC-245fa was 
found to be $9 \%$ in [9]. In addition to HFC-134a and HFC$245 \mathrm{fa}, \mathrm{CO}_{2}$ was also utilized as a working fluid in several solar ORC applications. For instance, Zhang et al. analyzed the performance of supercritical solar ORC, using $\mathrm{CO}_{2}[10]$. They revealed that the cycle efficiency was found to be $8.78-9.45 \%$. Another solar ORC system, using $\mathrm{CO}_{2}$ was examined by [11]. They reported that the solar collector generated heat with temperature of $165{ }^{\circ} \mathrm{C}$ and the cycle efficiency was $25 \%$. In order to address the variability nature of solar energy sensible heat storage (SHS) system has been used in solar ORCs [12]. For instance, a dynamic simulation study of flat-plate collectors based solar ORC system using an oil storage tank was conducted by [12]. Another solar ORC analysis, including SHS was performed in Ref. [13]. Wang et al. presented a regenerative solar ORC, where a thermal storage system was utilized to store the collected heat in the system [14]. In addition to SHSs, latent heat storage (LHS) systems can also be applied to solar thermal power applications $[15,16]$.

Selection of an appropriate working fluid is an important process as it has a crucial effect on the performance of ORCs. In addition to this, environmental and safety impacts of a fluid such as ozone depletion potential (ODP), global warming potential (GWP), flammability and toxicity should be considered. Therefore, working fluid selection studies for a small scale solar ORC have been conducted by several researchers [17]. A theoretical study of a solar ORC, where solar collector was employed as thermal energy source of the ORC was conducted by [18]. In their study, twelve thermofluids including hydrocarbons (HCs), Hydrofluorocarbons (HFCs) and ammonia were analyzed. A theoretical and experimental analysis of a solar ORC with FPC using HFC-134a, HFC-227ea and HFC-365mfc was performed by [19]. The results showed that HFC-365mfc was the most efficient fluid. Rayegan simulated a solar ORC, using 117 organic compounds. It was claimed that compounds with higher critical temperature are better options for ORC applications [3]. In another simulation study of a solar thermal power cycle, HFC-245fa and HFC-134a were recommended to be utilized as the working fluids of the cycle [20].

It is stated that for an efficient ORC application in terms of obtaining maximum power output from a heat source, the challenge lies in choosing an appropriate working fluid and defining the cycle parameters according to the selected fluid [21]. A small scale solar ORC, where a flat-plate collector was employed as the direct heat source was constructed and the experimental tests of the cycle were conducted in order to evaluate the performance characteristics of the cycle through energy analysis in this study. As the working fluid of the cycle, new generation HFE-7000 refrigerant was utilized. Then, the solar ORC was mathematically modeled to simulate the cycle using the same working fluid (HFE-7000). The simulations were performed under various expander pressures to determine its effect on the collector, the expander and the whole cycle performance. Finally, the optimum expander pressure that provides the maximum amount of net work output of the cycle was evaluated.

\section{NOMENCLATURE}

\begin{tabular}{|c|c|c|c|}
\hline \multicolumn{4}{|c|}{ Nomenclature } \\
\hline$A$ & area, $\mathrm{m}^{2}$ & $f$ & fluid \\
\hline$C_{p}$ & specific heat, $\mathrm{J} / \mathrm{kg} \mathrm{K}$ & $g$ & vapor \\
\hline$D$ & diameter, $\mathrm{m}$ & $i$ & Inner \\
\hline$e$ & eccentricity, m & in & inlet, incoming \\
\hline$F$ & fin efficiency & int & intake \\
\hline$F_{R}$ & heat removal factor & $l$ & liquid \\
\hline$h$ & $\begin{array}{l}\text { heat transfer coefficient, } \\
\mathrm{W} / \mathrm{m}^{2} \mathrm{~K}\end{array}$ & mec & mechanical \\
\hline$H$ & Enthalpy, J/kg & $o$ & outer \\
\hline$H_{f g}$ & Heat of vaporization, $\mathrm{J} / \mathrm{kg}$ & out & outlet \\
\hline$k$ & $\begin{array}{l}\text { thermal conductivity, } \\
\mathrm{W} / \mathrm{m} \mathrm{K}\end{array}$ & $o v$ & over \\
\hline$\stackrel{\circ}{m}$ & Mass flow rate, $\mathrm{kg} / \mathrm{s}$ & $p$ & plate \\
\hline$n$ & number of vanes & rot & rotor \\
\hline$r$ & radius, $\mathrm{m}$ & $s$ & isentropic \\
\hline$S$ & solar radiation, $\mathrm{W} / \mathrm{m}^{2}$ & $s p$ & single phase \\
\hline$T$ & temperature, ${ }^{\circ} \mathrm{C}$ & stat & stator \\
\hline$U$ & $\begin{array}{l}\text { heat loss coefficient, } \\
\mathrm{W} / \mathrm{m}^{2} \mathrm{~K}\end{array}$ & $t p$ & two phase \\
\hline$Q$ & heat, W & $T$ & total \\
\hline$V$ & Volume, $\mathrm{m}^{3}$ & $u$ & useful \\
\hline$W$ & work, kW & $\begin{array}{l}u d \\
w f\end{array}$ & $\begin{array}{l}\text { under } \\
\text { working fluid }\end{array}$ \\
\hline \multicolumn{4}{|c|}{ Subscripts } \\
\hline$a$ & Ambient & \multicolumn{2}{|c|}{ Greek symbols } \\
\hline col & Collector & $\tau \alpha$ & $\begin{array}{l}\text { absorbance } \\
\text { product }\end{array}$ \\
\hline cond & Condensation & $\delta$ & $\begin{array}{l}\text { absorber plate } \\
\text { thickness, mm }\end{array}$ \\
\hline$d s g$ & designed & $v$ & $\begin{array}{l}\text { specific volume, } \\
\mathrm{m}^{3} / \mathrm{kg} \\
\text { angle of a specific }\end{array}$ \\
\hline evap & evaporation & $\theta$ & $\begin{array}{l}\text { vane from the } \\
\text { origin }\end{array}$ \\
\hline exh & exhaust & $\eta$ & efficiency \\
\hline $\exp$ & expander & & \\
\hline
\end{tabular}

\section{EXPERIMENTAL}

A solar organic Rankine cycle test rig, utilizing HFE-7000 was built and commissioned to evaluate the cycle performance in this section. HFE-7000 refrigerant which is a Hydrofluoroether (HFE) is a non-ozone depleting refrigerant. It also has relatively low GWP [22]. The proposed system consists of a collector, a vane expander, a condenser, a liquid reservoir and a pump (Figure 1). The cycle operates on four main processes which are:

- compression of the liquid HFE-7000 from low pressure to high pressure (Figure 1, state 2) 
- conversion of solar radiation into heat and heat addition to the working fluid in the collector (Figure 1 , state 3)

- Expansion of HFE-7000 in the expander and generation of mechanical energy (Figure 1, state 4)

- Heat rejection and condensation of the working fluid in the condenser (Figure 1, state 1)

The specifications of each component of the solar ORC can be found in Ref. [23].

$\downarrow$ Mains water

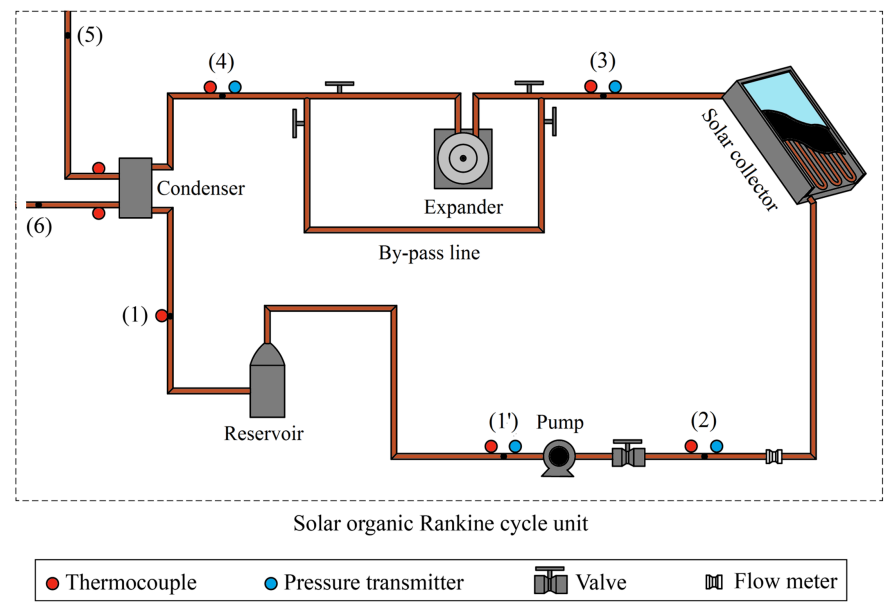

Figure 1 Schematic diagram of the solar ORC [23]

Initially, the leak test of the system was conducted prior to the system experiments to observe if there was any leakage somewhere in the system. As the cycle did not show any sign of leakage, $8 \mathrm{~kg}(5.7 \mathrm{~L})$ of working fluid was introduced into the cycle through the liquid reservoir. Then, the pump and the condenser were turned on to let the water and HFE-7000 circulates in the system with no heat input. This was performed to check the reliability of the system. Then, the data acquisition unit and the solar simulator were turned on to initiate the experiment. During the experiments, a solar simulator was used to provide a stable energy to the cycle. Initially, the expander by-pass line of the expander was on to avoid any liquid going through the expander. As the HFE-7000 temperature and pressures were monitored, the by-pass line of the expander was closed when the liquid reached the vapor conditions. Thus, the vapor expands in the expander and generates mechanical energy by rotating the expander shaft. Finally, post the expander, the fluid condensed in the condenser and was pumped to the flat-plate collector to complete the cycle. The experimental methodology, including the locations of the thermocouples and pressure transmitters, specification of the flow meter is comprehensively reported in Ref. [23]. During the experiment, an average radiation of 890 $\mathrm{W} / \mathrm{m}^{2}$ was supplied on the collector surface. A detailed description of the measurement of the radiation on the surface of the collector by using a pyranometer can be found in Ref. [23].

\section{THEORY}

\section{Flat-plate collector:}

Previously, the serpentine tube flat-plate collector which is utilized in this study was modeled and validated against experimental data in Ref. [24]. Initially, the solar energy on the absorber plate $\left(\mathrm{Q}_{\mathrm{p}}\right)$ and the useful energy $\left(\mathrm{Q}_{\mathrm{u}}\right)$ are calculated by using the formulas below;

$$
\begin{aligned}
& Q_{p}=A_{p}\left(S_{i n}(\tau \alpha)-U_{T}\left(T_{p}-T_{a}\right)\right) \\
& Q_{u}=A_{p} F_{R}\left(S_{i n}(\tau \alpha)-U_{T}\left(T_{f, \text { in }}-T_{a}\right)\right)
\end{aligned}
$$

$A_{p}, S_{i n}$ and $\tau \alpha$ represent the collector area, incoming solar radiation and transmittance-absorbance product respectively. The collector heat balance is shown in Figure 2.

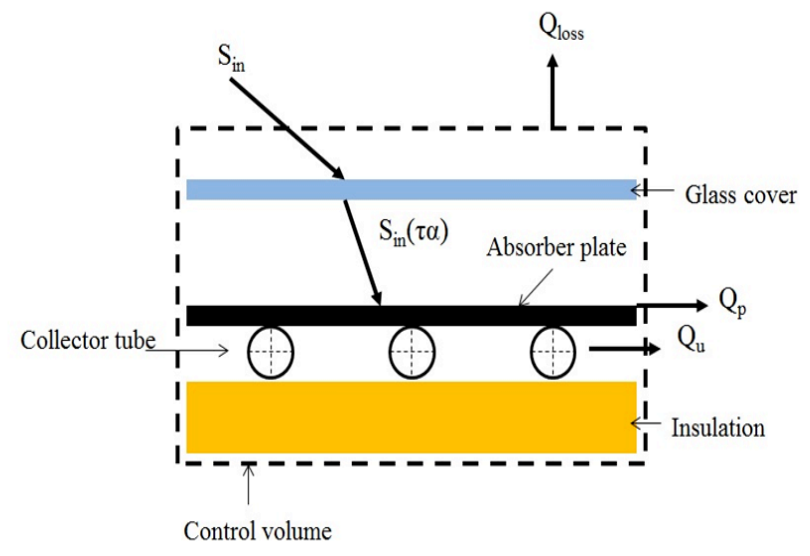

Figure 2 Collector heat balance

Therefore, the first product of the right hand side of Eq. (1-2) indicates the solar radiation travelling through the glass cover where some portion of the heat is lost to the ambient. $U_{T}$ is the total heat loss coefficient and it consists of the top and the back heat losses. The calculation of the total heat transfer coefficient was explained by Klein [25]. It is important to note that the edge heat transfer loss was neglected in this study. Then, some portion of the energy that is absorbed on the collector surface is also lost to the atmosphere through the convection losses and the remaining is transferred to the working fluid. The amount of the heat that is transferred to the working fluid is called 'useful energy' and it is calculated by using Eq. (2). The difference between Eq. (1) and Eq. (2) is that instead of the plate temperature $T_{p}$, fluid inlet temperature $T_{\text {fin }}$ is taken into account to calculate the heat transfer losses with the addition of the collector heat removal factor $\left(F_{R}\right)$. Equation (3) estimates the heat removal factor as:

$$
F_{R}=\frac{\dot{m} C_{p}}{A_{p} U_{T}}\left(1-\exp \left(-\frac{A_{p} U_{T} F^{\prime}}{\dot{m} C_{p}}\right)\right)
$$

where $F^{\prime}$ represents the collector efficiency factor and it is calculated by Equation (4); 


$$
F^{\prime}=\frac{\left(U_{T}\right)^{-1}}{W\left(U_{T}\left(D_{o}+\left(W-D_{o}\right) F\right)\right)^{-1}+\left(C_{b}\right)^{-1}+\left(\pi D_{i} h_{f}\right)^{-1}}
$$

where $\mathrm{F}$ indicates the fin efficiency.

$$
F=\frac{\tanh \left(m\left(W-D_{o} / 2\right)\right)}{m\left(W-D_{o} / 2\right)} ; \quad m=\sqrt{\frac{U_{T}}{k \delta}}
$$

In Equation (4), $h_{f}$ represents the heat transfer coefficient of the working fluid and it is estimated under two cases which are single phase and two-phase flow. The calculation of the heat transfer coefficient was explained comprehensively in Ref. [24].

\section{Vane expander:}

In the mathematical modelling of the expander, initially, the built-in volume ratio, which is the ratio of the working chambers' volumes at the end and of the expansion process and at the beginning of the expansion process was evaluated according to the geometrical characteristics of the expander [26]. The following formula was used to calculate the radius of the stator to the center of the rotor:

$$
d(\theta)=-e \times \sin \theta+\sqrt{\left(r_{\text {stat }}\right)^{2}-(e \times \cos \theta)^{2}}
$$

where $r$ and $e$ represent the eccentricity and radius. The volume of the working chamber as a function of the angular movement was calculated by using the formula below:

$$
V(\theta)=A(\theta) \times L_{\text {stat }}
$$

where $A(\theta)$ is the area of the working chamber and it can be determined as:

$$
A(\theta)=\frac{1}{2} \int_{\theta}^{\theta+\frac{2 \pi}{n}}\left(d(\theta)^{2}-r_{r o t}{ }^{2}\right) d(\theta)
$$

As the radius of the stator $\left(r_{\text {stat }}\right)$ and the rotor $\left(r_{\text {rot }}\right)$, length of the stator $\left(L_{\text {stat }}\right)$, the eccentricity $(e)$, intake $\left(\theta_{\text {int }}\right)$ and exhaust angles $\left(\theta_{\text {exh }}\right)$ are the known parameters, expander built-in volume ratio can be evaluated by using the formula below:

$r_{v}=\frac{V_{\text {exh }}}{V_{\text {int }}}$

In order to calculate the expander under and over- expansion losses, the designed pressure ratio of the expander was estimated as [27]:

$$
P R_{d s g}=\left(r_{v}\right)^{k}
$$

Under-expansion occurs if the operating pressure of the cycle $\left(\mathrm{P}_{\text {exp,in }} / \mathrm{P}_{\text {exp,out }}\right)$ is greater than the designed pressure ratio of the expander, otherwise over-expansion arises. As the designed pressure ratio was calculated (Eq. 10), the work output and the losses of the expander under the under-expansion and overexpansion cases can be determined as [28]:

$$
\begin{aligned}
& W_{\text {exp,ud }}=\dot{m}_{w f} \times\left(\begin{array}{l}
\left(H_{\text {exp,in }}-H_{\text {exp,out dsg }, s}\right) \\
+\left(v_{\text {exp }, \text { out }} \times\left(P_{\text {exp }, \text { out }, \text { dsg }}-P_{\text {exp,out }}\right)\right) \times 100
\end{array}\right) \times \eta_{\text {mec }} \\
& W_{\text {exp,ov }}=\dot{m}_{w f} \times\left(\begin{array}{l}
\left(H_{\text {exp,in }}-H_{\text {exp,out }, \text { dg }, s}\right) \\
-\left(v_{\text {exp }, \text { out }} \times\left(P_{\text {exp,out }, \text { dsg }}-P_{\text {exp,out }}\right)\right) \times 100
\end{array}\right) \times \eta_{\text {mec }}
\end{aligned}
$$

where $H$ and $v$ are the enthalpy and specific volume of the working fluid. $\eta_{m e c}$ represents the mechanical efficiency of the expander after frictional and heat transfer losses of the expander. In this study, the mechanical efficiency of the expander was taken as 0.7 [29].

\section{Condenser:}

The amount of the heat that is rejected from the condenser was calculated by using the following formula:

$$
\begin{aligned}
& Q_{\text {cond }}=\dot{\circ}_{w f} \times\left(H_{\text {cond }, \text { in }}-H_{g, \text { cond }}\right) \\
& +\dot{m}_{w f}\left(H_{g, \text { cond }}-H_{l, \text { cond }}\right)
\end{aligned}
$$

\section{Pump:}

The consumed work in the pump was estimated as follows:

$W_{\text {pump }}=\frac{\dot{m}_{w f} \times v_{\text {pump }, \text { in }} \times\left(P_{\text {evap }}-P_{\text {cond }}\right)}{\eta_{\text {pump }, s}}$

$\eta_{\text {pump,s }}$ represents the isentropic pump efficiency and it was taken as 0.6 .

\section{Simulation procedure:}

A computer code was developed in Matlab environment in order to simulate the proposed solar ORC. The fluid properties were taken from REFPROP 9.1 [30]. It is important to note that as HFE-7000 is a dry fluid, the system was modeled as a saturated cycle in other words, the fluid is saturated vapor and saturated liquid at the outlet of the collector and the condenser respectively. The pressure losses within the collector and the condenser were neglected. The simulations were performed at constant condensing temperature of $25{ }^{\circ} \mathrm{C}$ and various collector/expander pressure (1.06 - 4.27 bar). As it was mentioned that the pressure losses were assumed to be zero, corresponding saturation pressure at $25{ }^{\circ} \mathrm{C}$ represents the condensing pressure of the cycle. Similarly, corresponding temperature at collector/expander pressure indicates the evaporating temperature of the cycle. The simulation procedure starts with the calculation of the fluid properties at the collector inlet. As the fluid is saturated liquid at $25^{\circ} \mathrm{C}$ at the condenser outlet, the enthalpy at the collector inlet was calculated by using the formula below:

$H_{\text {col, in }}=w_{\text {pump }}+\left(H_{\text {cond }, \text { out }} \times 1000\right)$

where $w_{\text {pump }}$ represents the specific pump work and it can be determined as:

$$
w_{\text {pump }}=\frac{v_{\text {pump }, \text { in }} \times\left(P_{\text {evap }}-P_{\text {cond }}\right)}{\eta_{\text {pump }, s}}
$$

The collector inlet temperature can be evaluated as the collector inlet enthalpy and the collector pressure are known. The numerical procedure was based on dividing the collector tube into small elements and determining the fluid outlet temperature, collector plate temperature, the working fluid heat 
gain and the collector heat loss at the end of each element, as well as the collector outlet by using the known fluid temperature at the collector inlet and the fluid mass flow rate. The fluid entered the collector as a sub-cooled liquid and it gained energy as it circulated in the collector tube. The singlephase flow calculations were applied as the fluid remains in the sub-cooled region. When the fluid temperature reached the corresponding saturation temperature, then the two-phase flow calculations were utilized in the analysis. As the fluid vapor quality reached 1 before the end of the collector tube, the single phase flow calculations were applied again. Therefore, the fluid left the collector as a super-heated vapor at the evaluated temperature. However, in this study, the collector inlet and outlet temperatures and the collector inlet and outlet enthalpies are the known parameters as it was assumed that the fluid leaves the collector as saturated vapor at the corresponding collector pressure whereas the flow rate of the working fluid is an unknown parameter. Therefore, it is crucial to determine at which element the fluid reaches the saturation points to apply corresponding flow calculations (single or two-phase flow). Initially, the collector tube was considered as two regions which are single-phase and two-phase. In order to determine the transition element where the fluid goes into the saturated region, the iteration begins by assuming that the fluid reaches the saturation conditions after the first element. This means that, if it is assumed that the tube was divided into ' $j$ ' elements, the single phase region covers 1 element, whereas the twophase region covers $\mathrm{j}-1$ elements. Then, the mass flow rate was calculated iteratively for both the single-phase and two-phase regions:

$$
\begin{aligned}
\dot{m}_{w f, s p} & =\frac{Q_{\text {gain }, s p}}{\left(H_{\text {col,in }}-H_{l}\right)} \\
\stackrel{\circ}{w f, t p} & =\frac{Q_{\text {gain }, t p}}{\left(H_{g}-H_{l}\right)}
\end{aligned}
$$

The iteration continued until the following criterion was satisfied:

$\left|\stackrel{\circ}{m_{w f, s p}-m_{w f, t p}}\right| \leq 0.0001$

This point represents the number of elements where HFE-7000 reached saturation condition. The collector specifications, the description of the iterative method for the fluid and plate temperature calculations, heat gain of the fluid and the collector heat loss determinations were described comprehensively in Ref. [24]. Once the, working fluid mass flow rate was calculated, the expander calculations were started to determine the built-in volume ratio and the expander designed outlet pressure with the help of Eq. (9-10). Then, the code evaluated the mechanical work of the expander according to its operating case (under or over expansion) by using Eq. (11-12). Post expander, the amount of the rejected heat and the consumed pump work was determined by using Eq. (13-14) respectively. The simulation conditions were given in Table 1 .
Table 1 Parameters of the solar ORC simulations

\begin{tabular}{ll}
\hline Parameter & Value \\
\hline Solar radiation $\left(\mathrm{S}_{\text {in }}\right)$ & $800 \mathrm{~W} / \mathrm{m}^{2}$ \\
Condenser temperature $\left(\mathrm{T}_{\text {cond }}\right)$ & $25^{\circ} \mathrm{C}$ \\
Ambient temperature $\left(\mathrm{T}_{\mathrm{a}}\right)$ & $15^{\circ} \mathrm{C}$ \\
Expander pressure $\left(\mathrm{P}_{\text {exp }}\right)$ & $1.068-4.271 \mathrm{bar}$ \\
Expander mechanical efficiency $\left(\eta_{\text {mec }}\right)$ & 0.7 \\
Pump isentropic efficiency $\left(\eta_{\text {pump }}\right)$ & 0.6 \\
\hline
\end{tabular}

\section{Performance indicators:}

The efficiency of the collector, the expander and the solar ORC were evaluated according to the equations below:

$$
\begin{aligned}
& \eta_{\text {col }}= \frac{m_{w f}\left(\left(C_{p}\left(T_{\text {evap }}-T_{\text {col }, \text { in }}\right)\right)+\left(H_{g}-H_{l}\right)\right)}{S_{\text {in }} \times A_{\text {col }}} \\
& \eta_{\text {exp }}=\frac{W_{\text {exp }, \text { ud }}}{m_{w f} \times\left(H_{\text {exp }, \text { in }}-H_{\text {exp }, \text { out }, s}\right)}
\end{aligned}
$$

or

$$
\begin{aligned}
& \eta_{\text {exp }}=\frac{W_{\text {exp }, o v}}{m_{w f} \times\left(H_{\text {exp,in }}-H_{\text {exp out }, s}\right)} \\
& \eta_{\text {SORC }}=\frac{W_{\text {net }}}{Q_{\text {gain }}}
\end{aligned}
$$

where $W_{\text {net }}$ is the net work output of the solar ORC and it was estimated as:

$$
W_{n e t}=W_{\text {exp }}-W_{\text {pump }}
$$

\section{RESULTS AND DISCUSSION}

\section{Experimental results:}

The working fluid flow rate was held constant at 0.022 $\mathrm{kg} / \mathrm{s}$ during the experiments and all the thermodynamic properties of HFE-7000 at various states were taken from REFPROP 9.1 [30]. The temperature, pressure and enthalpy values of HFE-7000 at various states are given in Table 2. It can be seen that HFE-7000 entered the collector at 1.86 bar and $19.1^{\circ} \mathrm{C}$ as a sub-cooled liquid. Then, its temperature increased to $45.41{ }^{\circ} \mathrm{C}$ and whereas its pressure decreased to 1.32 bar due to the friction losses in the collector. According to the corresponding temperature and pressure values, the fluid left the collector as a superheated vapor and flows through the expander.

Table 2 State properties of HFE-7000 and water [23]

\begin{tabular}{cccccc}
\hline $\begin{array}{c}\text { State } \\
(\mathbf{N o})\end{array}$ & Phase & $\boldsymbol{m}(\mathbf{k g} / \mathbf{s})$ & $\mathbf{T}\left({ }^{\circ} \mathbf{C}\right)$ & $\begin{array}{c}\mathbf{P} \\
(\mathbf{b a r})\end{array}$ & $\begin{array}{c}\mathbf{h} \\
(\mathbf{k J} / \mathbf{k g})\end{array}$ \\
\hline 1 & Liquid & 0.022 & 19.54 & 0.66 & 223.56 \\
$1^{\prime}$ & Liquid & 0.022 & 18.73 & 0.57 & 222.57 \\
\hline
\end{tabular}




\begin{tabular}{lccccc}
\hline 2 & Liquid & 0.022 & 19.1 & 1.86 & 223.06 \\
3 & Gas & 0.022 & 45.41 & 1.32 & 385.07 \\
4 & Gas & 0.022 & 36.36 & 0.66 & 378.4 \\
5 & Liquid & 0.06 & 13.47 & 0.66 & 56.63 \\
6 & Liquid & 0.06 & 26.88 & 0.66 & 112.75 \\
\hline
\end{tabular}

In the expander, HFE-7000 expanded and its temperature and pressure reduced to $36.36{ }^{\circ} \mathrm{C}$ and 0.66 bar respectively. This is where the mechanical energy was generated by rotating the expander shaft. All the state points of HFE-7000 are represented on a T-s diagram Figure 3.

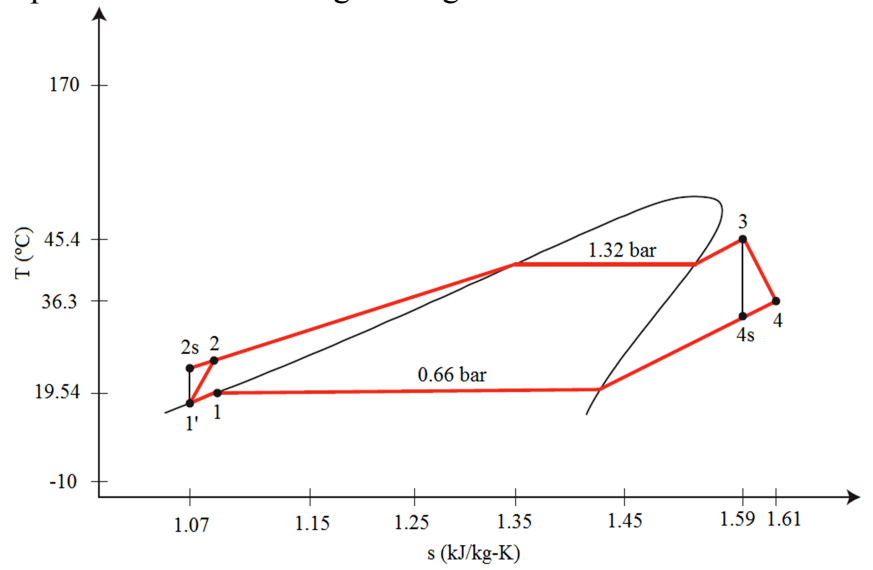

Figure 3 T-s diagram of HFE-7000 at various points [23]

Table 3 indicates that in the experiment, the collector received a $6194.4 \mathrm{~W}$ energy on its surface and $57.53 \%$ of this energy was transferred to the fluid as the useful heat gain of the fluid. The expander generated $146.74 \mathrm{~W}$ mechanical energy with an isentropic efficiency of $58.66 \%$. The similar efficiency value for a vane expander was reported in Ref. [31]. Finally, the net work output of the cycle was calculated as $135.96 \mathrm{~W}\left(\mathrm{~W}_{\text {pump }}=\right.$ $10.78 \mathrm{~W}$ ) and the thermal efficiency of the cycle was found to be $3.81 \%$ (Table 3$)$.

Table 3 Collector and expander analysis [23]

\begin{tabular}{lll}
\hline Component & Parameter & Value \\
\hline \multirow{3}{*}{ Flat-plate collector } & Incoming solar radiation & $6194.4(\mathrm{~W})$ \\
& Collector useful heat gain & $3564.2(\mathrm{~W})$ \\
& Collector efficiency & $57.53(\%)$ \\
\multirow{2}{*}{ Expander } & Expander work output & $146.74(\mathrm{~W})$ \\
& Expander efficiency & $58.66(\%)$ \\
Solar ORC & Net work output & $135.96(\mathrm{~W})$ \\
& Thermal efficiency & $3.81(\%)$ \\
\hline
\end{tabular}

\section{Simulation results:}

Figure 4 shows the variation of the collector efficiency, collector heat gain, the collector temperature and collector heat loss with the expander pressure. As it can be observed that collector efficiency and collector heat gain decreased from $57.81 \%$ and $3219 \mathrm{~W}$ to $41.95 \%$ and $2335.9 \mathrm{~W}$ respectively as the expander pressure rose from 1.068 bar to 4.271 bar.
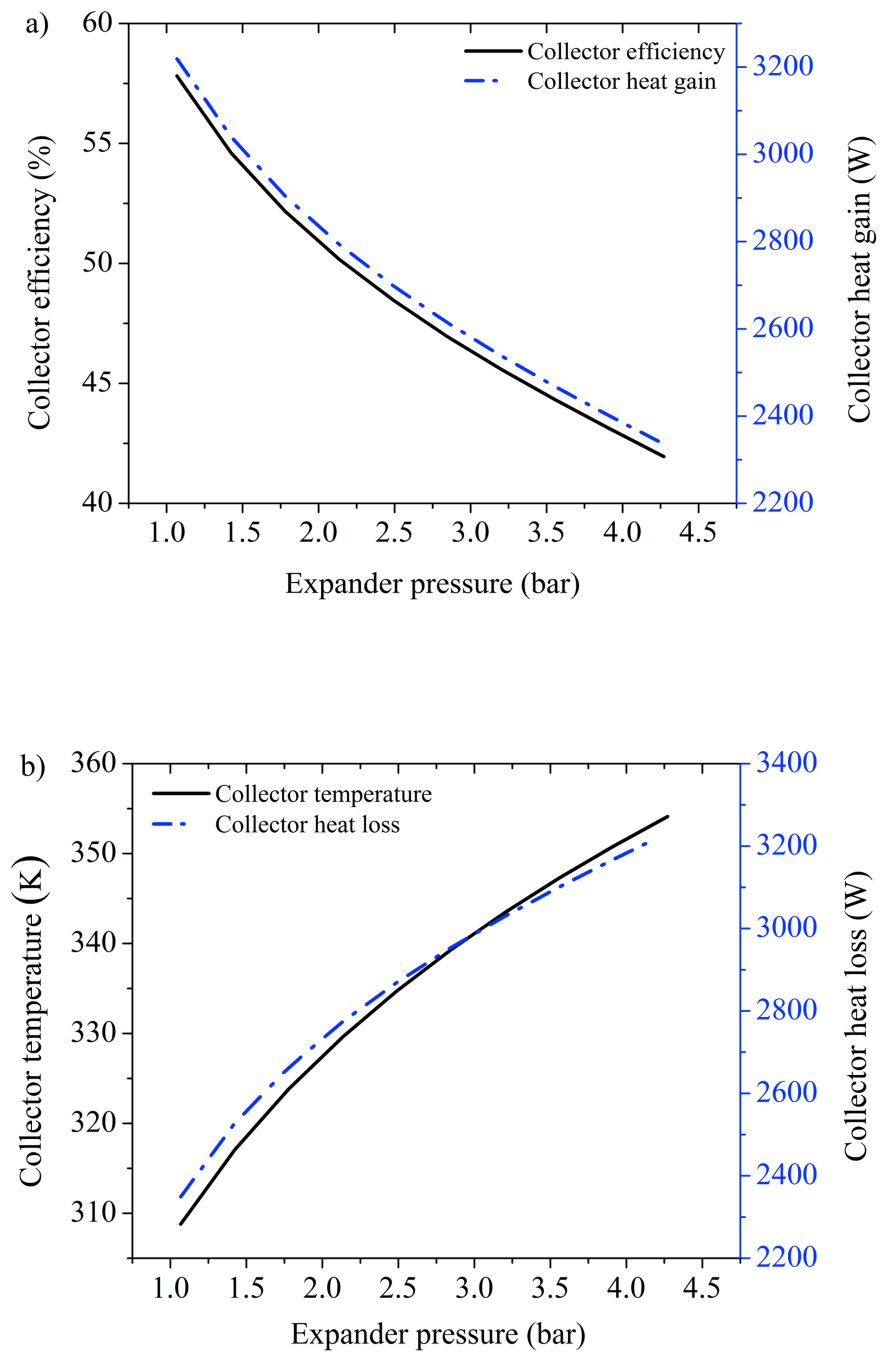

Figure 4 Collector analysis a) efficiency - heat gain b) temperature - heat loss

This can be explained by the fact that the increase in the expander inlet pressure in other words, in the collector pressure (the cycle is saturated) increased the fluid saturation points which resulted in a higher saturation temperature of the fluid, as well as a higher collector temperature. Due to the heat transfer losses from the collector to the ambient, the collector temperature and the collector heat losses augmented correspondingly as it can be seen from Figure 4. Similar findings were reported in Ref. [24].

The efficiency of the expander versus expander pressure is represented in Figure 5. The expander efficiency was $53.48 \%$ at 1.068 bar of expander pressure. This value increased to $69.13 \%$ as the expander pressure rose to 1.424 bar. These two expander pressure values fell on the left side of the dashed line which represents the over expansion case of the expander. Then, the expander efficiency reached its maximum value $(69.67 \%)$ at expander pressure of 1.78 bar. This is where the expander 
begins operating in under expansion case. After this point, the expander pressure decreased to $56.76 \%$ with the further increase in the expander pressure (Figure 5).

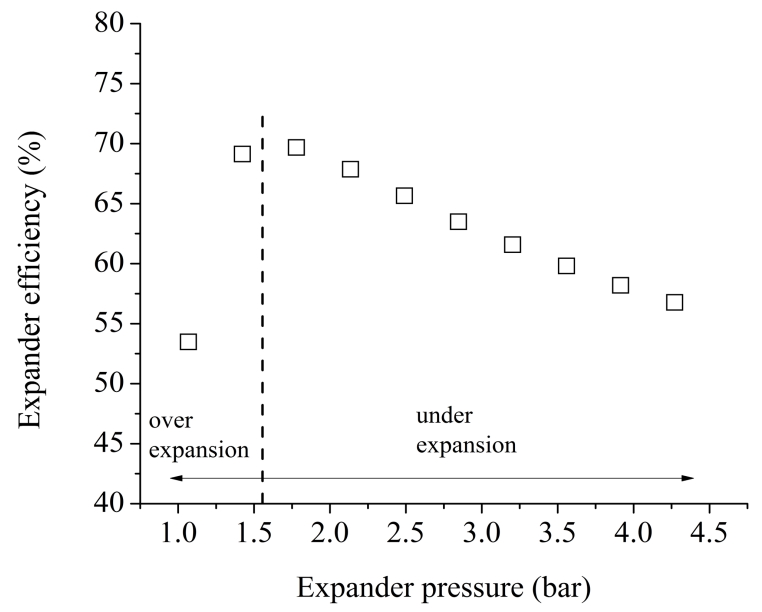

Figure 5 Expander efficiency versus expander pressure Figure 6 represents the generated net work and the solar ORC thermal efficiency. The net work of the cycle rose from 56.78 $\mathrm{W}$ to $170.08 \mathrm{~W}$ as the expander pressure increased from 1.068 bar to 3.55 bar. This is also where the net work output reached its maximum point.

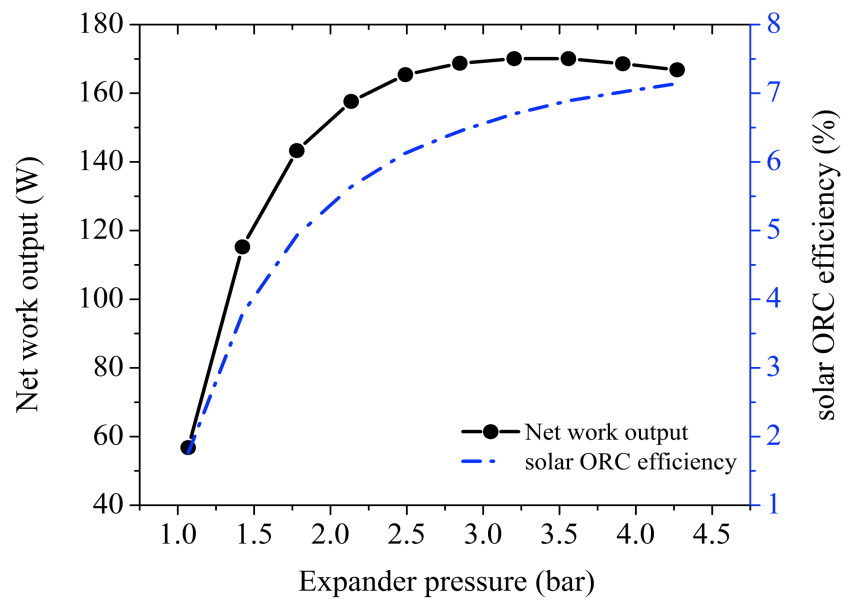

Figure 6 Solar ORC a) net work output b) thermal efficiency

This augmentation can be explained by the fact that as the condenser temperature/pressure is constant, the increase in the expander pressure caused a higher enthalpy drop in the expander which resulted in an higher net work output of the cycle. Although, the pump work was augmented and the flow rate of HFE-7000 decreased with the increase in the pressure, the negative effects of the increased pump work and diminished flow rate was smaller than the increase in the amount of the enthalpy drop. However, this trend has changed since the expander pressure increased from 3.55 bar to 4.27 bar as the net work output decreased to $166.8 \mathrm{~W}$. On the other hand, the thermal efficiency of the solar ORC continued to increase, yet the generated net work of the cycle did not enhance after the expander pressure of 3.55 bar. This is due to the drop in the amount of useful heat gain, which caused a gradual increase in the thermal efficiency of the cycle. Therefore, it is important to consider the thermal efficiency and the net work output of the cycle together where the collector (the direct heat source of the cycle) varies with the operating conditions such as expander pressure of the cycle.

Table 4 Optimization results of HFE-7000

\begin{tabular}{ll}
\hline Parameter & Value \\
\hline Expander pressure (bar) & 3.04 \\
Collector efficiency (\%) & 46.16 \\
Expander efficiency (\%) & 62.67 \\
Cycle efficiency (\%) & 6.62 \\
Net work output (W) & $\mathbf{1 7 0 . 4 3}$ \\
\hline
\end{tabular}

Regression analysis was conducted to predict net work output of the system, according to the expander pressure. The regression equation and the fitted line of the equation is represented in Figure 7. Optimization analysis was also performed to determine the optimum expander pressure value that provides the highest amount of the generated net work of the cycle. The optimization results were presented in Table 4. Optimization analysis indicated that the proposed cycle could generate $170.43 \mathrm{~W}$ of net work output with the thermal efficiency of $6.62 \%$ at 3.04 expander pressure.

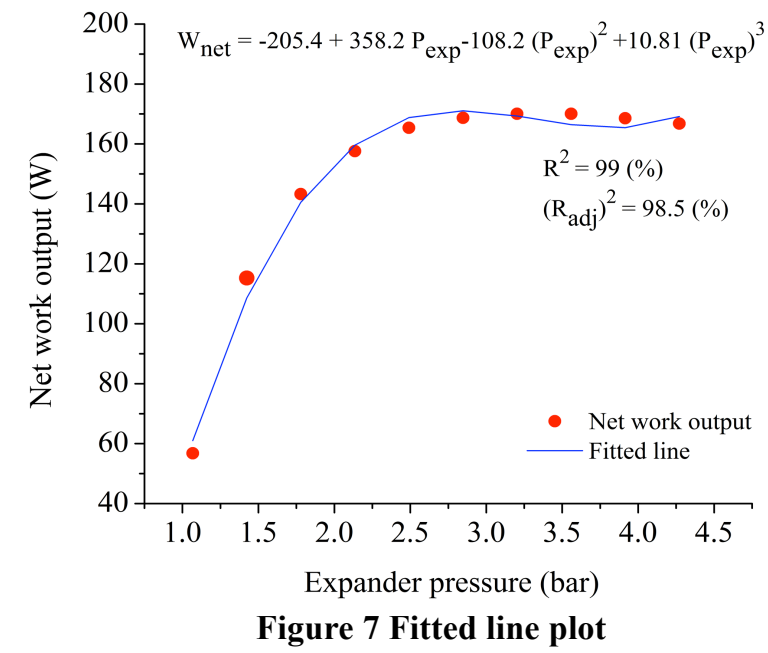

\section{CONCLUSION}

A small scale solar organic Rankine cycle was constructed and tested in this study. The cycle consists of a collector, an expander, a condenser and a pump. HFE-7000 was chosen as the working fluid of the cycle. Then, the system was numerically modeled as a saturated solar ORC and the simulations of the cycle were performed at a constant condenser temperature and various expander pressures. The experimental results showed that the flat-plate collector transferred $3564.2 \mathrm{~W}$ heat to the working fluid with the efficiency of $57.53 \%$. The expander efficiency was found to be 
$58.66 \%$. The proposed solar ORC provided $135.96 \mathrm{~W}$ with a thermal efficiency of $3.81 \%$. It was found from the simulation results that the expander pressure has a significant effect on the flat-plate collector, vane expander, as well as the cycle performance. For instance, increasing the expander pressure, which resulted in a rise in the collector saturation pressure/temperature, augmented the heat losses from the collector. Thus, the collector efficiency decreased with the increasing expander pressure $(41.95 \%)$. Similarly, the variation in the expander pressure caused the expander to operate under two expansion cases (under and over expansion) which resulted in various expander efficiencies (53.48-69.67\%). Therefore, the net work output of the cycle varied from $56.78 \mathrm{~W}$ to $170.08 \mathrm{~W}$ as the expander pressure increased from 1.068 bar to 4.271 . The optimization analysis showed that the cycle generated the highest amount of the net work output $(170.43 \mathrm{~W})$ at the expander pressure of $3.04 \mathrm{bar}$ and the corresponding cycle efficiency was found to be 6.62. In overall, both the experimental and simulation results revealed that HFE-7000 provides a moderate cycle performance and offers a viable alternative to be utilized in such cycles.

\section{ACKNOWLEDGMENTS}

The authors would like to acknowledge financial and inkind support provided by Bournemouth University, UK and Future Energy Sources (FES) Ltd. UK to conduct this research.

\section{REFERENCES}

[1] Chen, H., Goswami, D. Y., and Stefanakos, E. K., 2010, "A review of thermodynamic cycles and working fluids for the conversion of low-grade heat," Renewable and sustainable energy reviews, 14(9), pp. 3059-3067.

[2] Tchanche, B. F., Lambrinos, G., Frangoudakis, A., and Papadakis, G., 2011, "Low-grade heat conversion into power using organic Rankine cycles-a review of various applications," Renewable and Sustainable Energy Reviews, 15(8), pp. 3963-3979.

[3] Rayegan, R., and Tao, Y., 2011, "A procedure to select working fluids for Solar Organic Rankine Cycles (ORCs)," Renewable Energy, 36(2), pp. 659-670.

[4] Mavrou, P., Papadopoulos, A. I., Stijepovic, M. Z., Seferlis, P., Linke, P., and Voutetakis, S., 2015, "Novel and conventional working fluid mixtures for solar Rankine cycles: Performance assessment and multi-criteria selection," Applied Thermal Engineering, 75, pp. 384-396.

[5] Manolakos, D., Papadakis, G., Mohamed, E. S., Kyritsis, S., and Bouzianas, K., 2005, "Design of an autonomous lowtemperature solar Rankine cycle system for reverse osmosis desalination," Desalination, 183(1), pp. 73-80.

[6] Manolakos, D., Papadakis, G., Kyritsis, S., and Bouzianas, K., 2007, "Experimental evaluation of an autonomous lowtemperature solar Rankine cycle system for reverse osmosis desalination," Desalination, 203(1), pp. 366-374.

[7] Manolakos, D., Kosmadakis, G., Kyritsis, S., and Papadakis, G., 2009, "On site experimental evaluation of a low- temperature solar organic Rankine cycle system for RO desalination," Solar Energy, 83(5), pp. 646-656.

[8] Wang, X., Zhao, L., Wang, J., Zhang, W., Zhao, X., and Wu, W., 2010, "Performance evaluation of a low-temperature solar Rankine cycle system utilizing R245fa," Solar Energy, 84(3), pp. 353-364.

[9] Bryszewska-Mazurek, A., Świeboda, T., and Mazurek, W., 2011, "Performance Analysis of a Solar-Powered Organic Rankine Cycle Engine," Journal of the Air \& Waste Management Association, 61(1), pp. 3-6.

[10] Zhang, X.-R., Yamaguchi, H., and Uneno, D., 2007, "Experimental study on the performance of solar Rankine system using supercritical CO2," Renewable Energy, 32(15), pp. 2617-2628.

[11] Yamaguchi, H., Zhang, X., Fujima, K., Enomoto, M., and Sawada, N., 2006, "Solar energy powered Rankine cycle using supercritical CO 2," Applied Thermal Engineering, 26(17), pp. 2345-2354.

[12] Calise, F., d'Accadia, M. D., Vicidomini, M., and Scarpellino, M., 2015, "Design and simulation of a prototype of a small-scale solar CHP system based on evacuated flat-plate solar collectors and Organic Rankine Cycle," Energy Conversion and Management, 90, pp. 347-363.

[13] Freeman, J., Hellgardt, K., and Markides, C. N., 2015, "An assessment of solar-powered organic Rankine cycle systems for combined heating and power in UK domestic applications," Applied Energy, 138, pp. 605-620.

[14] Wang, J., Yan, Z., Wang, M., Ma, S., and Dai, Y., 2013, "Thermodynamic analysis and optimization of an (organic Rankine cycle) ORC using low grade heat source," Energy, 49, pp. 356-365.

[15] Khan, Z., Khan, Z., and Ghafoor, A., 2016, "A review of performance enhancement of PCM based latent heat storage system within the context of materials, thermal stability and compatibility," Energy Conversion and Management, 115, pp. 132-158.

[16] Khan, Z., Khan, Z., and Tabeshf, K., 2016, "Parametric investigations to enhance thermal performance of paraffin through a novel geometrical configuration of shell and tube latent thermal storage system," Energy Conversion and Management, 127, pp. 355-365.

[17] Aljundi, I. H., 2011, "Effect of dry hydrocarbons and critical point temperature on the efficiencies of organic Rankine cycle," Renewable Energy, 36(4), pp. 1196-1202.

[18] Delgado-Torres, A. M., and García-Rodríguez, L., 2010, "Analysis and optimization of the low-temperature solar organic Rankine cycle (ORC)," Energy Conversion and Management, 51(12), pp. 2846-2856.

[19] Marion, M., Voicu, I., and Tiffonnet, A.-L., 2012, "Study and optimization of a solar subcritical organic Rankine cycle," Renewable Energy, 48, pp. 100-109.

[20] Baral, S., and Kim, K. C., 2014, "Thermodynamic modeling of the solar organic Rankine cycle with selected organic working fluids for cogeneration," Distributed Generation \& Alternative Energy Journal, 29(3), pp. 7-34. 
[21] Vivian, J., Manente, G., and Lazzaretto, A., 2015, "A general framework to select working fluid and configuration of ORCs for low-to-medium temperature heat sources," Applied Energy, 156, pp. 727-746.

[22] Helvaci, H., and Khan, Z. A., 2017, "Heat transfer and entropy generation analysis of HFE 7000 based nanorefrigerants," International Journal of Heat and Mass Transfer, 104, pp. 318-327.

[23] Helvaci, H. U., and Khan, Z. A., 2016, "Experimental study of thermodynamic assessment of a small scale solar thermal system," Energy Conversion and Management, 117, pp. 567-576.

[24] Helvaci, H., and Khan, Z. A., 2015, "Mathematical modelling and simulation of multiphase flow in a flat plate solar energy collector," Energy Conversion and Management, 106, pp. 139-150.

[25] Klein, S., 1975, "Calculation of flat-plate collector loss coefficients," Solar Energy, 17(1), pp. 79-80.

[26] Quoilin, S., 2011, "Sustainable Energy Conversion Through the Use of Organic Rankine Cycles for Waste Heat Recovery and Solar Applications," University of Liège (Belgium.

[27] Gnutek, Z., and Kolasiński, P., 2013, "The application of rotary vane expanders in organic rankine cycle systemsthermodynamic description and experimental results," Journal of Engineering for Gas Turbines and Power, 135(6), p. 061901.

[28] Kim, Y. M., Shin, D. G., and Kim, C. G., 2014, "Optimization of design pressure ratio of positive displacement expander for vehicle engine waste heat recovery," Energies, 7(9), pp. 6105-6117.

[29] Kolasiński, P., 2015, "The Influence of the Heat Source Temperature on the Multivane Expander Output Power in an Organic Rankine Cycle (ORC) System," Energies, 8(5), pp. 3351-3369.

[30] Lemmon, E., Huber, M., and McLinden, M., 2013, "NIST reference database 23: reference fluid thermodynamic and transport properties-REFPROP, version 9.1," Standard Reference Data Program.

[31] Qiu, G., Shao, Y., Li, J., Liu, H., and Riffat, S. B., 2012, "Experimental investigation of a biomass-fired ORC-based micro-CHP for domestic applications," Fuel, 96, pp. 374-382. 